\title{
Electrophoretically-Deposited Solid Film Lubricants
}

\author{
M.T. Dugger, J.K.J. Panitz and C.W. Vanecek \\ Sandia National Laboratories \\ Albuquerque, NM 87185-0340
}

\begin{abstract}
An aqueous-based process that uses electrophoresis to attract powdered lubricant in suspension to a charged target has been developed. The deposition process yields coatings with low friction, complies with environmental safety regulations, requires minimal equipment, and has several advantages over processes involving organic binders or vacuum techniques. This work focuses on development of the deposition process, includes an analysis of the friction coefficient of the material in sliding contact with stainless steel under a range of conditions, and a functional evaluation of coating performance in a precision mechanical device application. The results show that solid lubricant films with friction coefficients as low as 0.03 can be produced. A 0.03 friction coefficient is superior to solid lubricants with binder systems, and is comparable to friction coefficients generated with more costly vacuum techniques.
\end{abstract}




\section{Introduction}

The useful tribological properties of molybdenum disulfide $\left(\mathrm{MoS}_{2}\right)$ are well known. ${ }^{1-24}$ The lubricating ability of pure $\mathrm{MoS}_{2}$ is associated with weak van der Waals' bonding between adjacent basal planes of the hexagonal crystal lattice which permit deformation of the crystal at low values of shear stress, and unlike graphite, does not depend on intercalation for low friction performance. Hence $\mathrm{MoS}_{2}$ is a suitable lubricant for vacuum and inert environments, and its performance is insensitive to temperature from cryogenic to more than $600^{\circ} \mathrm{C}$ in vacuum.

Elements of miniature mechanical assemblies such as the stronglink switch, a weapon safety component, are sometimes coated with dry film lubricants to improve their long term tribological performance. Required properties of these lubricant coatings are: chemical stability for 25 to 30 years, the ability to withstand temperature cycling and vibration (fretting), low and consistent friction coefficient throughout the useful life of the device, and minimum generation of debris due to wear. The trend toward reduced use of materials which may endanger the environment, occupational safety or public health place additional constraints on lubricant formulations and deposition methods which make many commercial formulations undesirable. Candidate solid lubricants for these applications suffer from several major drawbacks. Proprietary lubricant formulations containing the lubricating pigment $\left(\mathrm{MoS}_{2}\right.$ or other metal dichalcogenides, graphite, etc., or a combination) in an epoxy or phenolic binder are typically applied by spraying, in which case it is difficult to obtain a uniform coating on a substrate of complex shape. These preparations may be inappropriate for applications in which precise dimensional tolerances must be maintained. The solvents used in these preparations frequently require special handling, such as personal protective equipment and exhaust gas scrubbers. Recent years have seen the introduction of commercial preparations which are more environmentally benign, ${ }^{25}$ but coating uniformity problems persist. Vacuum sputter deposition processes for $\mathrm{MoS}_{2}$ circumvent several of the potential problems encountered with liquid preparations. First, the process uses no hazardous solvents, so the process waste stream is minimal. In situ cleaning may be accomplished by reverse sputtering with inert gas ions. The sputtering process also permits close control of deposition rate, and films only a fraction of a micron thick are capable of millions of contact cycles. ${ }^{22}$ At these thicknesses, the tolerance stack-up created by the presence of the lubricant film may effectively be ignored. Several advances have been made in recent years to increase the density of sputtered $\mathrm{MoS}_{2}$ films, thereby reducing their vulnerability to degradation in environments containing water vapor. ${ }^{18}$ These include operating at lower gas pressures, ${ }^{19,20}$ concurrent ion bombardment during film growth, ${ }^{21}$ and periodic passivation of active growth sites with metallic interlayers. ${ }^{22}$ Modern sputtered films are amenable to a degree of compositional and microstructural control that was not possible with early sputtered films, and they possess concomitant improvements in performance. However, inherent disadvantages with the sputtering process remain. Conditioning of new $\mathrm{MoS}_{2}$ targets or those which have been exposed to atmosphere for extended periods is required before reproducible coatings can be generated. Substrates of complex shape require shaped electrodes or complex fixturing to obtain uniform coatings. Finally, vacuum processing is inherently expensive. 


\section{DISCLAIMER}

This report was prepared as an account of work sponsored by an agency of the United States Government. Neither the United States Government nor any agency thereof, nor any of their employees, make any warranty, express or implied, or assumes any legal liability or responsibility for the accuracy, completeness, or usefulness of any information, apparatus, product, or process disclosed, or represents that its use would not infringe privately owned rights. Reference herein to any specific commercial product, process, or service by trade name, trademark, manufacturer, or otherwise does not necessarily constitute or imply its endorsement, recommendation, or favoring by the United States Government or any agency thereof. The views and opinions of authors expressed herein do not necessarily state or reflect those of the United States Government or any agency thereof. 


\section{DISCLAIMER}

Portions of this document may be illegible in electronic image products. Images are produced from the best available original document. 
In this paper we report on a process for electrophoretically ${ }^{26}$ depositing coatings of $\mathrm{MoS}_{2}$ and composite coatings containing $\mathrm{MoS}_{2}$ and graphite from an aqueous bath. This deposition process shares many of the benefits of the sputter deposition process, and avoids many of the possible disadvantages. The deposition parameters affecting electrophoretic deposition provide insight into solid/liquid interface phenomena. Tribological characterization of the coatings reveals performance characteristics and environmental dependencies similar to those seen in sputtered films. Functional evaluation of mechanical assemblies lubricated electrophoretically provide a 'proof-of-concept' for this deposition technique, while also demonstrating the need for rigorous testing under the contact conditions present in the application prior to deployment of a new coating process.

\section{Experimental}

\section{A. Deposition}

Stable, electrophoretically-active baths of $\mathrm{MoS}_{2}$ were prepared by adding $0.5-2.5 \mathrm{wt} . \%$ of 98\% pure $\mathrm{MoS}_{2}$ powder [Alfa Products (Johnson Matthey Co.), Danvers, MA] with an average (sedographic) particle size of $1.2 \mu \mathrm{m}$ to $18 \mathrm{M} \Omega \cdot \mathrm{cm}$ deionized water. In order to wet and disperse the $\mathrm{MoS}_{2}$ particles, $0.03 \pm 0.004 \mathrm{~g}$ or more of a nonionic surfactant such as polyethylene glycol nonylphenol ether (Triton $\mathrm{X} 100^{\circledR}$ from Fisher Scientific Co., Pittsburgh, PA) was added to a $60 \mathrm{ml}$ bath and the mixture gently shaken. Sonication of fresh baths for 30-60 minutes at $40 \mathrm{kHz}$ in a commercial ultrasonic cleaner resulted in baths which displayed a useful shelf life in excess of 2 weeks. Two metal electrodes consisting of $1 \mathrm{~cm}$ wide strips of commercial purity nickel foil, immersed in a bath and biased at 20-120 V across a 1.5-3.0 $\mathrm{cm}$ gap, resulted in a thin matte gray coating on the cathode in 15-120 seconds. For parameter screening experiments, $60 \mathrm{ml}$ baths were prepared and $10 \mathrm{ml}$ volumes extracted for deposition under different conditions. When coating large areas $\left(4 \mathrm{~cm}^{2}\right)$ at high voltages $(>50 \mathrm{~V})$ in small bath volumes $(10 \mathrm{ml})$ for $30-120 \mathrm{~s}$, bath temperatures approach $80^{\circ} \mathrm{C}$ and baths with high surfactant concentration foamed under these conditions. An ice bath was found to be effective in cooling these baths and reduced foaming. Trace amounts of reagent grade acids, ammonium hydroxide, and inorganic salts were added to some baths to explore the effects of different ionic composition. We have also found that tungsten diselenide ( $\left.\mathrm{WSe}_{2}\right)$ particles can be deposited from aqueous dispersion with a trace amount of a nonionic surfactant using process parameters essentially identical to those used to deposit $\mathrm{MoS}_{2}$ particles.

Aqueous dispersions with 0.5 to $2.5 \mathrm{wt} . \%$, micrometer-sized graphite particles plus 0.03 to $0.10 \mathrm{~g}$ Triton $\mathrm{X} 100^{\circledR}$ in a $60 \mathrm{ml}$ bath are not electrophoretically active when $75 \mathrm{~V}$ is applied across an electrode spacing of $1.5 \mathrm{~cm}$. However mixtures containing 10 to $90 \mathrm{wt} . \% \mathrm{MoS}_{2}$ plus 90 to $10 \mathrm{wt} . \%$ graphite that are dispersed in water with a trace of surfactant are electrophoretically active. After preparation, small samples were decanted from each $\mathrm{MoS}_{2}$ plus graphite mixed bath. A nickel foil substrate was placed at the bottom of a flat dish with a decanted suspension, then the liquid was allowed to evaporate at room temperature in lab air. The dried $\mathrm{MoS}_{2}$ plus graphite solids collected from each mixed bath composition were used as calibration standards for Raman spectroscopy. This strategy was used to investigate whether the ratio of $\mathrm{MoS}_{2}$ plus graphite used to prepare the baths was similar to the ratio of $\mathrm{MoS}_{2}$ plus graphite present in the electrophoretically deposited coatings. 


\section{B. Composition and Structure}

Raman spectroscopy (514.5 nm laser light) was used to compare the composition, electron energy band structure and crystallinity of electrophoretically-deposited $\mathrm{MoS}_{2}$ to sputtered $\mathrm{MoS}_{2}$ and the starting $\mathrm{MoS}_{2}$ powder. X-ray photoelectron spectroscopy (XPS) was performed to evaluate potential interactions of the coatings with water vapor after storage in environments containing $98 \%$ relative humidity at room temperature. Coating thickness, uniformity and structure were observed using optical and scanning electron microscopy (SEM). Transmission electron microscopy (TEM) performed on representative $\mathrm{MoS}_{2}$ coatings deposited directly on carbon-coated TEM grids were used to determine the crystallinity and orientation of the films. Auger electron spectroscopy (AES) was performed to elucidate changes in the film composition with sliding in different environments. For friction tests in vacuum, AES was performed in situ, without exposing the worn surfaces to the ambient atmosphere. A $10 \mathrm{keV}, 10 \mathrm{nA}$ electron beam was used, and rectangular areas (approx. $40 \mu \mathrm{m} \times 50 \mu \mathrm{m}$ ) that fit within the wear track without overlapping unworn regions were employed to determine the worn surface composition. Published sensitivity factors ${ }^{27}$ were used to compute atomic concentration from the spectral data.

\section{Tribological Characterization}

Bath volumes of $60 \mathrm{ml}$, a commercial purity nickel electrode of approximately $20 \mathrm{~cm}^{2}$ surface area, and an electrode spacing of $3 \mathrm{~cm}$ were used to coat 304 and $440 \mathrm{C}$ stainless steel substrates for friction measurements. A submicrometer thick layer of nickel was electrodeposited on some disks, between the substrate and the lubricant film, to investigate effects on coating uniformity. Stainless steel substrates were $2.5 \mathrm{~cm}$ in diameter and $0.1 \mathrm{~cm}$ thick, with a nominal arithmetic surface roughness $\left(R_{a}\right)$ of $25 \mathrm{~nm}$ obtained by metallographic polishing. Specimens were cleaned ultrasonically in reagent grade acetone followed by isopropyl alcohol prior to coating.

A pin-on-disk device was used for all friction measurements. A new 440C stainless steel pin with $0.79 \mathrm{~mm}$ diameter hemispherical tip was used for each test. Surface finishing and cleaning of the pin was similar to that of the disk substrates. The friction coefficient was measured continuously at an applied load of $35 \mathrm{gf}$ (1.1 GPa peak contact stress), and a sliding speed of $2 \pm 1 \mathrm{~cm} / \mathrm{s}$ for 2000 cycles or coating failure (defined as a rapid and irreversible increase in the friction coefficient above 0.4 ), whichever occurred first. Test environments consisted of laboratory air (48-55\% relative humidity, room temperature), ultrahigh purity $\mathrm{N}_{2}$ $\left(<10\right.$ ppm $\mathrm{O}_{2}$, dew point $\left.<-65^{\circ} \mathrm{C}\right)$ and vacuum $\left(\mathrm{P}_{\text {tot }}<1 \times 10^{-6} \mathrm{~Pa}\right)$. At least three duplicate experiments were performed per deposition/test condition.

\section{Functional Evaluation}

The Detonator Safing Stronglink (DSSL) device was chosen to illustrate the concept of lubricating substrates of complex shape. The part chosen for lubrication was a wire rope (three bundles of seven 304L steel wires) with a nominal outside diameter of $0.09 \mathrm{~cm}$, sliding inside a 304L steel casing to deliver bi-directional motion from an electromechanical actuator 
to a mechanical discriminator. The actuator displaces the wire rope a distance of approximately $0.15 \mathrm{~cm}$ in each direction within the casing. At the discriminator, the wire rope is connected to a plunger which drives a toothed wheel. The discriminator mechanism puts a tensile force of approximately $3.11 \mathrm{~N}$ on the wire rope during a pull (actuator pulling the wire rope out of the discriminator), and a compressive force of $1.78 \mathrm{~N}$ during a push (actuator pushing the wire rope into the discriminator). During testing of the prototype for this device, wear was observed between the uncoated wire rope and the casing which caused the forces required to operate the device to rise rapidly to unacceptable levels. Experiments have been performed previously with a variety of coatings in an attempt to prevent wear between the wire rope and casing. Quantitative force measurements were available from those experiments, providing an opportunity to compare data on electrophoretically deposited $\mathrm{MoS}_{2}$ with existing data from more traditional coatings containing organic binders.

Six wire ropes electrophoretically lubricated with pure $\mathrm{MoS}_{2}$ were cycled 6000 times on a hydraulically driven force versus displacement tester (MTS model 810 with a model 458 controller). For each test, a fresh casing was used. The load at the discriminator end of the wire rope was simulated using two springs which applied a push load of $1.60 \mathrm{~N}$ and a pull load of $3.42 \mathrm{~N}$. These forces correspond to the forces that the discriminator mechanism places on the wire rope during operation. The casing was wrapped over a shaped fixture which duplicates the configuration of the casing in service. The forces required to push and pull the wire rope inside the casing were measured quasi-statically with the force versus displacement tester after initial set up and at 1500 cycle intervals until the end of the test. A push/pull cycle frequency of $8.3 \mathrm{~Hz}$ was used to accumulate sliding cycles on the rope/casing couple between force measurements. Tests were performed in laboratory air at 20 to $21^{\circ} \mathrm{C}$.

\section{Results and Discussion}

\section{A. Deposition}

The process parameters affecting electrophoretic deposition include bath composition (lubricant particle size, surfactant concentration, $\mathrm{pH}$ and ionic additives), forming voltage, deposition time and substrate material. While sputter deposition can produce a wide range of coating morphologies and properties, ${ }^{16,19-22}$ electrophoretic deposition appears to produce coatings with essentially identical properties within a well-defined process parameter window. Electrophoretic deposition process parameters affecting coating quality are discussed individually below.

Micrometer-sized particles are essential for preparing a bath that produces useful coatings. Particles larger than 3-5 $\mu \mathrm{m}$ can not be maintained in suspension long enough for deposition without strong agitation and/or the addition of stabilizers, such as zein (purified cornstarch, from Fisher Scientific) or nitrocellulose. These additions, while producing baths with large particles, may compromise deposition rate, uniformity, or purity, and impose limits on minimum coating thickness. Nonionic surfactant concentration is critically important to obtain coatings with useful properties. Solutions with insufficient surfactant aggregate and sediment after extended sonication or during storage. In addition, sufficient surfactant must be added to prevent the particles from coagulating as they approach one another en route to 
the substrate. Extensive coagulation results in low deposition rates, sedimentation of large aggregates near the cathode/substrate, and preferential deposition onto high electric field sites. A minimum concentration of $0.03 \mathrm{~g}$ Triton $\mathrm{X} 100^{\circledR}$ in $60 \mathrm{ml}$ water $(490 \mathrm{ppm})$ with $1.5 \mathrm{~g} \mathrm{MoS}$ powder with an average particle size of $1.2 \mu \mathrm{m}$ is required to prepare a stable suspension. Triton $\mathrm{X} 100^{\circledR}$ additions of $70 \mathrm{ppm}$ in excess of this minimum amount improve bath stability and coating uniformity. Surfactant concentrations in excess of $0.06 \mathrm{~g}$ per $60 \mathrm{ml}$ of $2.5 \mathrm{wt} . \%$ suspensions foam excessively, particularly if the temperature of the bath is allowed to rise during electrolysis. Experiments with an alternative nonionic surfactant (Tergitol, ${ }^{\circledR}$ from Union Carbide Corp., alkyloxypolyethylenenoxpropylenoxyisopropanol) indicated similar mechanisms were occurring at slightly different surfactant concentrations. The addition of trace amounts of acetic acid, nitric acid, or ammonium hydroxide to adjust the $\mathrm{pH}$ of the electrolyte detracts from process efficiency and coating uniformity. Similarly, addition of trace amounts of nickel acetate or silver nitrate (with the expectation of codepositing nickel or silver and improving coating adhesion and performance) adversely affects the process, such that large amounts of energy are consumed in transporting ionic species rather than $\mathrm{MoS}_{2}$ particles. Sonication of the baths for 30-60 minutes during initial preparation results in more consistent electrical resistivities and denser, more uniform coatings, which may result from the breakup of weakly bound agglomerates in the as-received $\mathrm{MoS}_{2}$ powder.

$\mathrm{MoS}_{2}$ coatings could not be deposited at forming voltages below $20 \mathrm{~V}$ across a $1.5 \mathrm{~cm}$ electrode spacing. This may indicate that some minimum electric field strength is required to overcome steric hindrance and allow $\mathrm{MoS}_{2}$ particles to bond to the substrate. The deposition rate initially increases as the applied voltage is increased. Water electrolytically dissociates into hydrogen and oxygen gas, which leads to extensive foaming at high power levels. Foaming occurred at $120 \mathrm{~V}$ in $10 \mathrm{ml}$ cell volumes within two minutes, while $150 \mathrm{~V}$ could be used in $60 \mathrm{ml}$ cell volumes with greater electrode spacings $(\$ 3.0 \mathrm{~cm})$. The large thermal mass of the $60 \mathrm{ml}$ baths reduced heating during the two minutes required to deposit a coating.

Deposition time affects both coating thickness and uniformity. Coatings initially deposit on high field areas. The electrical resistance of $\mathrm{MoS}_{2}$ (with a $1.2 \mathrm{eV}$ band gap) screens the applied field and effectively reduces the deposition rate in these areas, allowing deposition on other areas. After approximately 2 minutes, a $1-2 \mu \mathrm{m}$ thick coating of $\mathrm{MoS}_{2}$ covers the cathode (substrate) and the deposition rate slows considerably. Research on sputtered films indicates that coating thicknesses of $1 \mu \mathrm{m}$ possess low friction and high durability. ${ }^{27,28}$ Films significantly thicker than this may accumulate excessive wear debris that may interfere with the operation of precision mechanisms or contaminate optical surfaces.

The substrate material also affects coating quality. In general, uniform $\mathrm{MoS}_{2}$ coatings which exhibit low friction coefficient form within a wide range of process parameters on substrates where there is an opportunity for chemical reaction between sulfur and the substrate metal (e.g. nickel and copper). Higher forming voltages can be used to produce uniform coatings on metals that react less readily with sulfur. As-deposited coatings formed on stainless steel friction test specimens were less uniform than those formed on nickel and copper sheet. Mechanical wear or deliberate burnishing prior to service densifies these coatings and creates a more uniform finish. 


\section{B. Composition and Structure}

The Raman spectra shown in Figure 1 reveal that the electrophoretic coatings have narrow, well-defined Raman bands characteristic of the stoichiometric crystalline material. Broadening of the fundamental Raman vibrational modes at $286 \mathrm{~cm}^{-1}\left(\mathrm{E}_{1} \mathrm{~g}\right), 382 \mathrm{~cm}^{-1}\left(\mathrm{E}_{2} \mathrm{~g}\right.$, related to Mo-S bonding in the basal plane), and $409 \mathrm{~cm}^{-1}\left(\mathrm{~A}_{1} \mathrm{~g}\right.$, related to the S-S distance along the c-axis) indicate that the sputtered material is more amorphous, i.e. lacks the long range crystallinity present in the electrophoretic material. Raman spectroscopy also indicates that the coatings deposited from mixed $\mathrm{MoS}_{2}$ plus graphite baths contain ratios of graphite and $\mathrm{MoS}_{2}$ that approximate the bath composition. However, baths with $100 \%$ graphite are not electrophoretically active. These results suggest that the electrophoretically active $\mathrm{MoS}_{2}$ particles drag along and entrain the intrinsically electrophoretically inactive graphite particles.

Electron diffraction patterns from these films are also characteristic of good quality, stoichiometric, crystalline material (Fig. 2). Tilting of the specimen on the TEM stage indicates that basal plane reflections are absent, i.e. that the as-deposited coatings show a preferred orientation with basal planes parallel to the substrate surface. This observation suggests that the electrophoretic activity of $\mathrm{MoS}_{2}$ particles dispersed in Triton $\mathrm{X} 100^{\circledR}$ and water is due to a net positive electrostatic charge on the surface basal planes of sulfur. According to this mechanism, the surfactant molecule would orient with the glycol (hydrophilic) end toward the water, and the ether end (hydrophobic) toward the $\mathrm{MoS}_{2}$ particle, as shown in Figure 3.

XPS analysis indicated that electrophoretically deposited $\mathrm{MoS}_{2}$ coatings contain 2-12 at.\% $\mathrm{Ni}$ and $0.4-1.0$ at.\% $\mathrm{Cu}$ (from the commercial purity anode, possibly), as shown in Table 1. Samples stored for several months at $98 \%$ relative humidity at room temperature did not exhibit oxidative degradation observed in rf sputtered films stored under similar conditions. ${ }^{17}$ Thin coatings deposited at low forming voltages and temperatures are more susceptible to degradation, but burnishing the films immediately after deposition improves the oxidation resistance.

\section{Tribological Characterization}

The role of various deposition process parameters, the presence of a nickel adhesion layer, and the effect of substrate composition on the friction coefficient of electrophoretically deposited $\mathrm{MoS}_{2}$ films were investigated by performing friction measurements in a nitrogen atmosphere. Experiments were typically run for a total of 2000 contact cycles, as this represents sufficient contact duration to establish steady-state sliding conditions. Figure 4 shows a typical plot of the coefficient of friction (COF) as a function of the number of disk revolutions, or contact cycles. After a brief run-in period during which the film is mechanically deformed and redistributed over the wear track, a stable value of the friction coefficient develops, which persists throughout the remainder of the test.

Figure 5 illustrates the effect on the final $\mathrm{COF}$ of changing deposition conditions for electrophoretic $\mathrm{MoS}_{2}$ coatings on 304 stainless steel substrates. An electrolytically deposited layer of nickel between the substrate and the coating was used to promote uniformity. The 
data show that no benefits are obtained by continued deposition after the 1-2 $\mu$ m layer of $\mathrm{MoS}_{2}$ has been formed on the surfaces. In fact, increased friction coefficient for longer deposition times on unburnished samples indicates that the coating uniformity may be compromised by excessive heating and foaming of the bath. Larger surfactant concentrations and burnishing produce lower friction coefficient due to the formation of more uniform coating morphology. The added surfactant acts to insure that the $\mathrm{MoS}_{2}$ micelles are surrounded with a sheath of surfactant, as shown in Figure 3, to prevent agglomeration and settling of the suspension. Burnishing serves to fuse and densify the as-deposited particles, and mechanical deformation due to sliding results in an even smoother morphology (Fig. 6).

The role of the nickel layer and bath temperature in coating friction performance were investigated next. Figure 7 shows the friction coefficient after 2000 cycles for a variety of deposition conditions. The figure indicates that the nickel intermediate layer is not required to yield a coating with low friction coefficient. Coatings deposited from uncooled baths without a nickel layer produced friction coefficients comparable to those where a nickel layer was present, within the variability of the data. The coating deposited from a chilled bath without a nickel interlayer produced the lowest friction coefficients. Cooling the bath helps reduce foaming and improves coating uniformity, and results in improved tribological performance. Exceptionally high friction coefficients were observed for the coating deposited from a chilled bath and employing a nickel interlayer. This failure is associated with poor adhesion of the nickel layer, which delaminated under stress and caused failure of the coating. Since acceptable performance can be obtained without the use of nickel intermediate layers, and because these present additional complexity and opportunity for failure, the nickel layers were omitted for the remainder of the work.

Figure 8 illustrates the effect of substrate material on the friction coefficient of electrophoretically deposited $\mathrm{MoS}_{2}$ films. Within the experimental uncertainty, the friction coefficient of burnished films is constant over the factor of three variation in cell voltage shown. The data also indicate that the performance benefits afforded by burnishing the films to densify and redistribute the coating make additional deposition time unnecessary (i.e. the $50 \mathrm{~V}$ deposition runs in Fig. 8; compare 1 minute plus burnish with 2 minutes without burnish). The coating deposited at a cell voltage of $150 \mathrm{~V}$ for 2 minutes on 304 stainless steel exhibits a high average friction coefficient for five duplicate experiments, due to coating failure (COF $>0.4)$ in two of the runs. The friction coefficient was similar to the response of the other films in Fig. 8 for the remainder of the runs. This inconsistent response from the coating is attributable to nonuniformities in the film, created by water electrolysis and surfactant foaming under the high voltage and long time (and hence high bath temperature) conditions present during this deposition run. Remarkably, the friction coefficient produced on $440 \mathrm{C}$ stainless steel substrates under identical deposition conditions ( $150 \mathrm{~V}, 2$ minutes) is slightly lower than for any of the other deposition conditions. This difference may be due to the different mechanical properties of the substrates; the high hardness of the $440 \mathrm{C}$ disks $(\$ 58$ Rockwell C) results in good intrinsic metal-to-metal adhesive wear resistance and the $\mathrm{MoS}_{2}$ film deposited on the surface under these conditions, although nonuniform, creates a transfer film which also contributes to reduced adhesion. 
Composite films of $\mathrm{MoS}_{2}$ and graphite were deposited electrophoretically on 304 stainless steel substrates in an effort to produce lubricant films that do not suffer from the well known environmental sensitivity of each of these materials. $\mathrm{MoS}_{2}$ exhibits low friction in vacuum and inert atmospheres, and higher friction in environments containing water vapor. The trend for graphite is just the opposite since adsorption of atmospheric gases, particularly water vapor, is required to intercalate the lamellar structure and lower the friction coefficient. By forming composite coatings with these constituents, we hoped to produce coatings that exhibit more uniform friction coefficient over a wide range of environmental conditions. Figure 9 compares the friction coefficient after 2000 cycles of sliding for four different electrophoretically deposited composite films when testing in laboratory air and vacuum. The effect on the tribological performance for pure $\mathrm{MoS}_{2}$ films sliding in laboratory air with $\$ 50 \%$ relative humidity, compared to earlier data when sliding in dry $\mathrm{N}_{2}$, is apparent in Fig. 9(a). The friction coefficient in air averaged 0.28 , compared to approximately 0.05 in dry nitrogen. However, as the amount of graphite in the films increases, a reduction in the friction coefficient is observed. The average friction coefficient in air for films containing $50 \mathrm{wt} \%$ $\mathrm{MoS}_{2}$ is identical to those containing just $17 \mathrm{wt} . \%$, within the certainty of the data. Figure 9(b) shows that in vacuum, pure $\mathrm{MoS}_{2}$ films exhibit coefficients of friction identical to those observed in a pure nitrogen ambient. Addition of $50 \mathrm{wt} . \%$ does not degrade the performance of the coating in vacuum. For higher fractions of graphite, the abrasive nature of this material in vacuum causes failure of the coating and adhesive interaction between the pin and the electrophoretically lubricated substrate. Compositional analysis of the as-deposited and worn surfaces by AES is presented in Figure 10. The figure shows that carbon is the dominant species on all unworn surfaces, and that carbon content increases with increasing graphite in the deposition bath. At the same time, sulfur and molybdenum concentrations on unworn surfaces decrease as the graphite in the deposition bath increases. These observations are consistent with the Raman results that showed the composite films to have approximately the same concentration of $\mathrm{MoS}_{2}$ and graphite as the baths used in their deposition. Composition data for films worn in air always exhibit a decrease in sulfur and molybdenum, and an increase in oxygen relative to the as-deposited surfaces. Air worn surfaces exhibit a S/Mo ratio near 2:1. This behavior is also observed for sputtered films, and is due to dynamic oxidation of the $\mathrm{MoS}_{2}$ during tribological contact in air. Sliding in vacuum produces surfaces that are much richer in sulfur than the air worn surfaces, with S/Mo ratios typically greater than 3:1. The S/Mo ratio on vacuum worn surfaces may exceed that on the as-deposited surface. The results of compositional analysis of vacuum worn films is also consistent with those for sputtered films, and reflects exposure of the easily sheared sulfur-rich basal planes of $\mathrm{MoS}_{2}$ in environments where oxygen is absent. The presence of large amounts of iron on vacuum worn surfaces for the $34 \mathrm{wt} . \%$ and $17 \mathrm{wt} . \% \mathrm{MoS}_{2}$ coatings is indicative of coating failure, which is also reflected in the friction coefficient data in Figure 9(b). In these tests, direct contact of the steel surfaces has occurred, mechanically alloying the coating with the underlying material.

\section{Functional Evaluation}

Pre-test inspection of the coated DSSL wire ropes showed that the electrophoretic deposition process left a thin film of $\mathrm{MoS}_{2}$ on the wires that formed the outside diameter of the rope, and a thick coating on wires inset from the outside diameter due to the wrap of the 
wires into a rope. For each test, a wire rope was placed inside a casing on the test fixture and cycled within the casing as described in the experimental section. Pull and push force as a function of cycle are displayed graphically in Figure 11. The pull and push forces were found to increase throughout the test. Post-test inspection of the wire ropes showed that the coating characteristics (thin on the outer diameter, with accumulated material on the interior wires) had not changed significantly from the pre-test condition of the wire ropes. In order to compare the effectiveness of the electrophoretic $\mathrm{MoS}_{2}$ in this application with other lubricants evaluated in an earlier program, the pull and push forces must be converted into efficiency using the equation

$$
\text { Efficiency }=\left[1 / 2\left(\frac{0.77}{\text { PullForce }}+\frac{0.36}{\text { PushForce }}\right)\right] \times 100 \%
$$

since the push and pull forces applied by the springs which simulate the discriminator loads were not identical in all the experimental setups. The equation shows that as push and pull forces increase with wire rope cycling, the coating efficiency decreases. Figure 12 compares the coating efficiency of the electrophoretically lubricated wire rope to efficiencies of three other protective coatings and an uncoated wire rope. Of primary concern for proper operation of the DSSL is the rate of change of coating efficiency with number of cycles. From Fig. 12 it appears that the efficiency rate of change for electrophoretic $\mathrm{MoS}_{2}$ is comparable to that of lubricants A (proprietary formulation containing $\mathrm{MoS}_{2}$, metallic oxides, and corrosion inhibitors in an epoxy-phenolic matrix, applied by hand spraying) and B (proprietary formulation containing $\mathrm{MoS}_{2}$ and graphite in a thermosetting resin, applied by hand spraying). Lubricant $\mathrm{C}$ (a proprietary formulation containing $\mathrm{MoS}_{2}$, metallic oxides and corrosion inhibitors in a low volatile constituent carrier) performed better, with a low rate of efficiency decrease. The efficiency drop for the uncoated rope during the first 1500 cycles was extreme. Even larger drops in efficiency were observed for other groups of units manufactured with uncoated wire ropes during the DSSL development phase. Based on the observed rate of efficiency decrease, the electrophoretic $\mathrm{MoS}_{2}$ coating would perform satisfactorily in this application, although the conventional binder/matrix materials performed as well or better. The relatively poor performance of the electrophoretic material is associated with the volume of lubricant present compared to that of the binder/matrix formulations. The thickness of conventional hand sprayed coatings is typically much greater than the $1-2 \mu \mathrm{m}$ present in the electrophoretic coating, and the conventional coatings were deliberately not burnished, to provide the maximum possible volume of lubricant between the wire rope and the casing. As the lubricants wear, debris is held captive within the casing and is available to be redistributed in the contact areas. The thick binder/matrix coatings generate copious amounts of debris, while the electrophoretic coatings will tend to generate relatively fewer particles, and these will be $\$ 1 \mu \mathrm{m}$ in diameter. Despite the confining geometry of the casing, the amount of debris generated by the electrophoretically deposited coating is probably insufficient to maintain a continuous transfer film of $\mathrm{MoS}_{2}$ over all contacting surfaces. It should also be noted that these experiments were performed in air, where electrophoretic $\mathrm{MoS}_{2}$ exhibits high friction coefficients (Fig. 9). The performance of electrophoretic $\mathrm{MoS}_{2}$ coatings is expected to improve when the device is operated in its normal (inert gas) environment. 


\section{Summary and Conclusions}

Electrophoretically deposited lubricants containing $\mathrm{MoS}_{2}$ display extremely low friction coefficients. This deposition process offers several advantages not readily available with alternative processes involving proprietary liquid paints, pastes, and sputter deposition. Electrophoretic deposition produces relatively pure, crystalline, stoichiometric coatings that are uniform on substrates of complex shape within a well-defined process window. Aqueous electrophoretic baths with $0.5-2.5$ wt.\% lubricant powder $\left(\mathrm{MoS}_{2}\right.$ or $\mathrm{MoS}_{2}+$ graphite) having an average particle size of $1.2 \mu \mathrm{m}$ and $500-1000 \mathrm{ppm}$ of a nonionic surfactant (Triton $\mathrm{X} 100^{\circledR}$ ), cell voltages from 50 to $100 \mathrm{~V}$ and bath temperatures from 8 to $80^{\circ} \mathrm{C}$ result in excellent lubricant films after approximately 2 minutes deposition time. Composite coatings electrophoretically deposited from baths containing $50 \mathrm{wt} . \% \mathrm{MoS}_{2}$ and graphite (in the lubricant powder phase) exhibited lower friction in air than pure $\mathrm{MoS}_{2}$, without compromising coating performance under vacuum conditions. The composition of worn surfaces in air and vacuum follows trends seen with sputter deposited films, i.e. dynamic oxidation of $\mathrm{MoS}_{2}$ when sliding in air and exposure of sulfur-rich basal planes when sliding in vacuum. Comparison of the performance of electrophoretically deposited pure $\mathrm{MoS}_{2}$ with more traditional liquid paint formulations revealed the importance of a captive contact geometry that retains solid lubricant debris in the vicinity of the contact for redistribution.

\section{Acknowledgments}

The authors wish to express thanks to Elizabeth Sorroche for performing the friction experiments and AES analysis, Dave Tallant and Regina Simpson for Raman spectroscopy, Charles Hills for TEM analysis, and Diane Peebles and Tony Ohlhausen for XPS analysis. The contributions of Greg Herman and Pat Schleitweiler at EG\&G Mound (Miamisburg, OH) during the functional evaluation of DSSL hardware are also greatly appreciated. This work was supported at Sandia National Laboratories by the U.S. Department of Energy under contract number DE-AC04-94AL85000.

\section{References}

1. P.D. Fleischauer, ASLE Trans. 27 (1984) 82.

2. R.T.K. Baker and R.D. Sherwood, in Microbeam Analysis 1986, edited by A.D. Romig and W.F. Chambers (San Francisco Press, San Francisco, CA, 1986), p.317.

3. T.P. Stewart and P.D. Fleischauer, Inorg. Chem. 21 (1982) 2426.

4. T. Spalvins, J. Vac. Sci. Technol. A5 (1987) 212.

5. M.N. Gardos, Lubricat. Eng. 32 (1976) 463.

6. E.W. Roberts, in Proceedings of the 20th Aerospace Mechanics Symposium, Cleveland, OH, 7-9 May 1986 (NASA, Washington, DC,1986), NASA Conf. Publ. No. 2423, p.103.

7. V. Buck, Wear 114 (1987) 263.

8. T. Spalvins, Thin Solid Films 96 (1982) 17.

9. T. Spalvins, Thin Solid Films 73 (1980) 291.

10. H. Dimigen, H. Hubsch, P. Willich, and K. Reichelt, Thin Solid Films 129 (1985) 79.

11. R. I. Christy, Thin Solid Films 80 (1981) 289.

12. V. Buck, Thin Solid Films 139 (1986) 157. 
13. M. Nishimura, M. Nosak, M. Suzuki, and E. Y. Miyakawa, in Proceedings of the $2^{\text {nd }}$ Annual Conference on Solid Lubrication (American Society of Lubrication Engineers, Park Ridge, IL, 1978), p 128.

14. V. Buck, Wear 91 (1983) 281.

15. H. Kuwano and K. Nagai, J. Vac. Sci. Technol. A3 (1985) 1809.

16. J.K.G. Panitz, L.E. Pope, C.R. Hills, J.E. Lyons, and D.J. Staley, Thin Solid Films 154 (1987) 323.

17. J.K.G. Panitz, L.E. Pope, J.E. Lyons, and D.J. Staley, J. Vac. Sci. Technol. A6 (1988) 1166.

18. J. R. Lince, J. Mater. Res. 5 (1990) 218.

19. A. Aubert, J.-Ph. Nabot, J. Ernoult, and Ph. Renaux, Surf. Coat. Technol. 41 (1990) 127.

20. J.-Ph. Nabot, A. Aubert, R. Gillet, and Ph. Renaux, Surf. Coat. Technol. $43 / 44$ (1990) 629.

21. R.N. Bolster, I.L. Singer, J.C. Wegand, S. Fayeulle, and C. R. Gossett, Surf. Coat. Technol. 46 (1991) 207.

22. M.R. Hilton, R. Bauer, S.V. Didziulis, M.T. Dugger, J.K. Keem, and J. Scholhamer, Surf. Coat. Technol. 53 (1992) 13.

23. M.R. Hilton, R. Bauer, and P.D. Fleischauer, Thin Solid Films 188 (1990) 219.

24. M.R. Hilton, R. Bauer, S.V. Didziulis, and P. D. Fleischauer, Thin Solid Films 201 (1991) 49.

25. C. Beal, EM Lubricants Company, Inc., private communication.

26. C. Guitierrez, J. Mosely, and T. Wallace, J. Electrochem. Soc. 109 (1962) 923.

27. L.E. Davis, N.C. MacDonald, P.W. Palmberg, G.E. Riach and R.E. Weber, eds., Handbook of Auger Electron Spectroscopy, Physical Electronics Industries, Inc.: Eden Prairie, MN (1976). 


\section{Tables}

Table 1 - XPS Atomic Concentration ${ }^{*}$

\begin{tabular}{|l|l|c|c|c|c|c|c|}
\hline \multicolumn{2}{|c|}{ Specimen Description } & \multicolumn{5}{c|}{ Atomic Concentration, \% } \\
\hline & & S & Mo & C & O & Ni & Cu \\
\hline not burnished & as-deposited & 29.8 & 16.2 & 32.1 & 19.1 & 2.4 & 0.4 \\
\hline & 4 mos. @ 98\% rel. humidity & 20.7 & 11.3 & 43.0 & 20.6 & 3.7 & 0.7 \\
\hline burnished & as-deposited & 17.7 & 10.3 & 38.7 & 27.5 & 5.3 & 0.6 \\
\hline & 4 mos. @ 98\% rel. humidity & 28.2 & 16.0 & 37.1 & 15.9 & 2.0 & 0.7 \\
\hline
\end{tabular}

${ }^{*} \mathrm{MoS}_{2}$ films were electrophoretically deposited on nickel foil from $2 \mathrm{wt} \% \mathrm{MoS}_{2}, 60 \mathrm{ml}$ baths without cooling (heated to $\sim 30^{\circ} \mathrm{C}$ after two minutes deposition). 


\section{List of Figures}

1. Raman spectra of bulk $\mathrm{MoS}_{2}$ and $\mathrm{MoS}_{2}$ coatings.

2. Electron diffraction pattern displayed by an electrophoretically deposited $\mathrm{MoS}_{2}$ coating on a carbon coated TEM grid.

3. Proposed structure of an electrophoretically active $\mathrm{MoS}_{2}$ micelle in water with a nonionic surfactant.

4. Friction coefficient as a function of contact cycles for electrophoretically deposited pure $\mathrm{MoS}_{2}$ on 304 stainless steel in a nitrogen ambient. The coating was deposited at a $50 \mathrm{~V}$ cell voltage for 1 minute from a $60 \mathrm{ml}, 2.0 \mathrm{wt} . \% \mathrm{MoS}_{2}$ bath containing $0.03 \mathrm{gm}$ of nonionic surfactant, and burnished after deposition. The solid line represents the mean value, and the dotted lines the extreme values as a function of cycle.

5. Friction coefficient after 2000 sliding cycles as a function of film deposition conditions. Films were deposited on 304 stainless steel substrates that were first given an electrolytic coating of nickel. The coatings were deposited from $60 \mathrm{ml}$ baths containing $2.0 \mathrm{wt} \%$ $\mathrm{MoS}_{2}$ particles, and the Triton $\mathrm{X} 100^{\circledR}$ volumes indicated. The error bars represent one standard deviation of five tests about the mean.

6. Micrographs showing electrophoretically deposited $\mathrm{MoS}_{2}$ coatings. High magnification scanning electron micrographs show discrete particles of $\mathrm{MoS}_{2}$ as-deposited, with the basal planes parallel with the substrate (a - left view), and after a light burnishing which fuses and densifies the particles ( $\mathrm{a}$ - right view). The worn surface (b) has an even smoother morphology after mechanical deformation, and many of the remaining large (1-2 $\mu \mathrm{m})$ features have been smoothed.

7. Friction coefficient after 2000 sliding cycles as a function of film deposition conditions. Films were deposited on 304 stainless steel substrates. The coatings were deposited from $60 \mathrm{ml}$ baths containing $2.0 \mathrm{wt} . \% \mathrm{MoS}_{2}$ particles. The indicated solutions were kept cool $\left(\sim 8^{\circ} \mathrm{C}\right.$ after two minutes) during deposition by surrounding the cell with an ice bath, while the others were allowed to heat $\left(\sim 30^{\circ} \mathrm{C}\right.$ after two minutes) during deposition. The error bars represent one standard deviation of five tests about the mean.

8. Friction coefficient after 2000 sliding cycles as a function of substrate material, for several different deposition process parameters. (a) shows results for 304 stainless steel substrates, and (b) shows results for $440 \mathrm{C}$ stainless steel substrates, heat treated to maximum hardness. The error bars in the figure represent one standard deviation of 5 tests about the mean.

9. Friction coefficient of composite electrophoretic $\mathrm{MoS}_{2}$ /graphite coatings on 304 stainless steel as a function of the wt. $\% \mathrm{MoS}_{2}$ in the particulate phase of the bath used to prepare the coatings. Results represent the steady-state friction coefficient after 2000 cycles of sliding against $440 \mathrm{C}$ in laboratory air (a) and vacuum (b). The error bars in the figure represent one standard deviation of 5 tests about the mean.

10. AES composition analysis of as-deposited and worn composite coatings whose friction results are shown in Figure 9. Results are shown for coatings deposited from baths whose solid particulates were (a) $100 \mathrm{wt} . \% \mathrm{MoS}_{2}$, (b) $50 \mathrm{wt} . \% \mathrm{MoS}_{2}$, (c) $34 \% \mathrm{MoS}_{2}$ and (d) 17 wt. $\% \mathrm{MoS}_{2}$.

11. Results of a functional evaluation of an electrophoretically-lubricated 304L wire rope sliding inside a $304 \mathrm{~L}$ casing. The forces required to pull (a) and push (b) the wire rope inside the casing against springs which simulate device loads at the other end of the wire 
rope are shown, as a function of number of actuation cycles. Error bars represent one standard deviation about the mean.

12. Calculated efficiency (see equation in text) for electrophoretically deposited $\mathrm{MoS}_{2}$ compared to commercial lubricants, as a function of actuation cycles. $\square=$ lubricant $A$ $\left(\mathrm{MoS}_{2}\right.$, metallic oxides and corrosion inhibitors in an epoxy-phenolic binder), $\mathbf{\square}=$ lubricant $\mathrm{B}\left(\mathrm{MoS}_{2}\right.$ and graphite in a thermosetting resin binder), $\mathrm{O}=$ lubricant $\mathrm{C}\left(\mathrm{MoS}_{2}\right.$, metallic oxides and corrosion inhibitors in a low volatile constituent binder), $\varnothing=$ bare cable (not lubricated), $\bullet=$ electrophoretically deposited $\mathrm{MoS}_{2}$. The error bars represent one standard deviation about the mean for the electrophoretic material. Uncertainties are similar for other lubricants. 


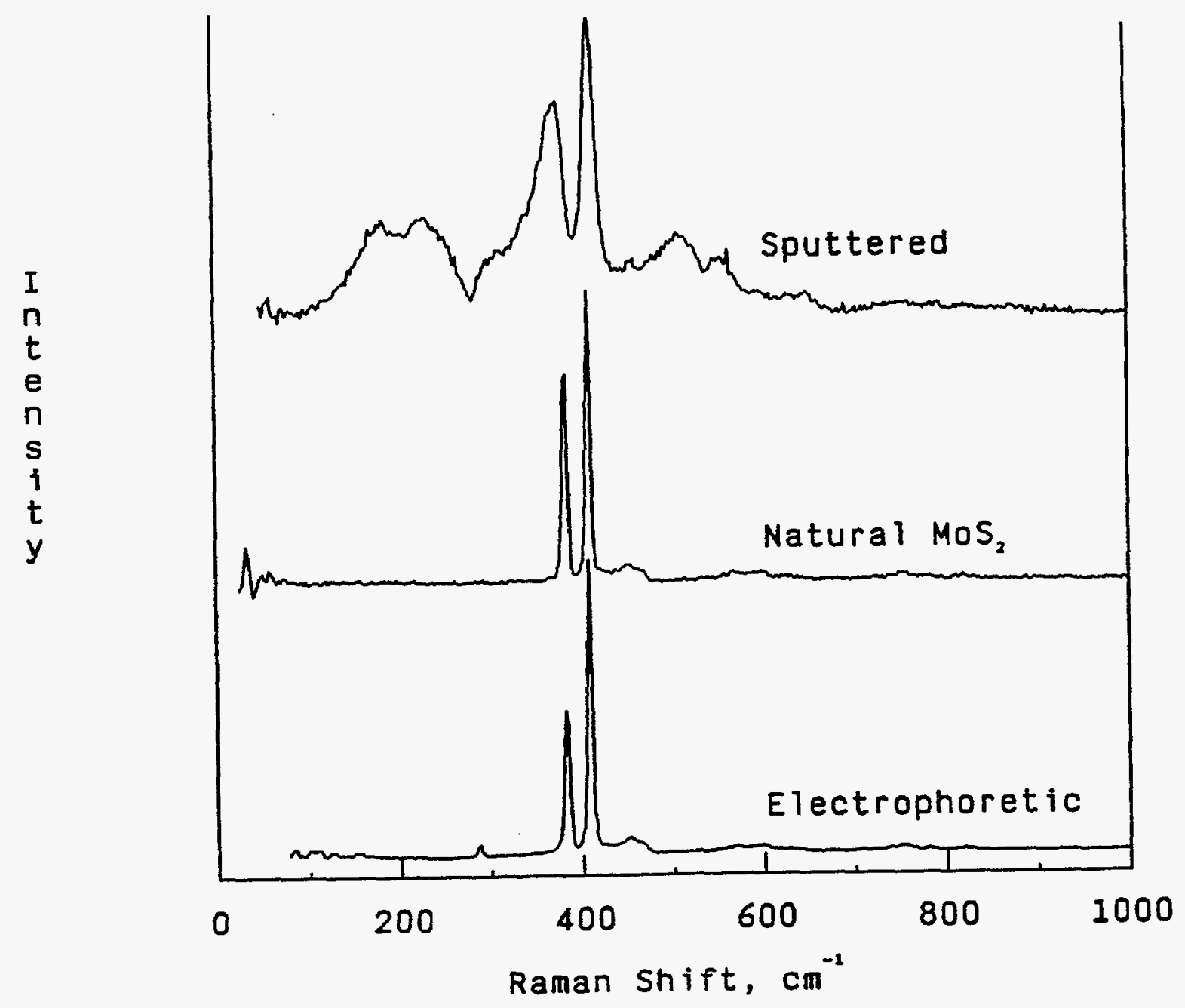

Figure 1 


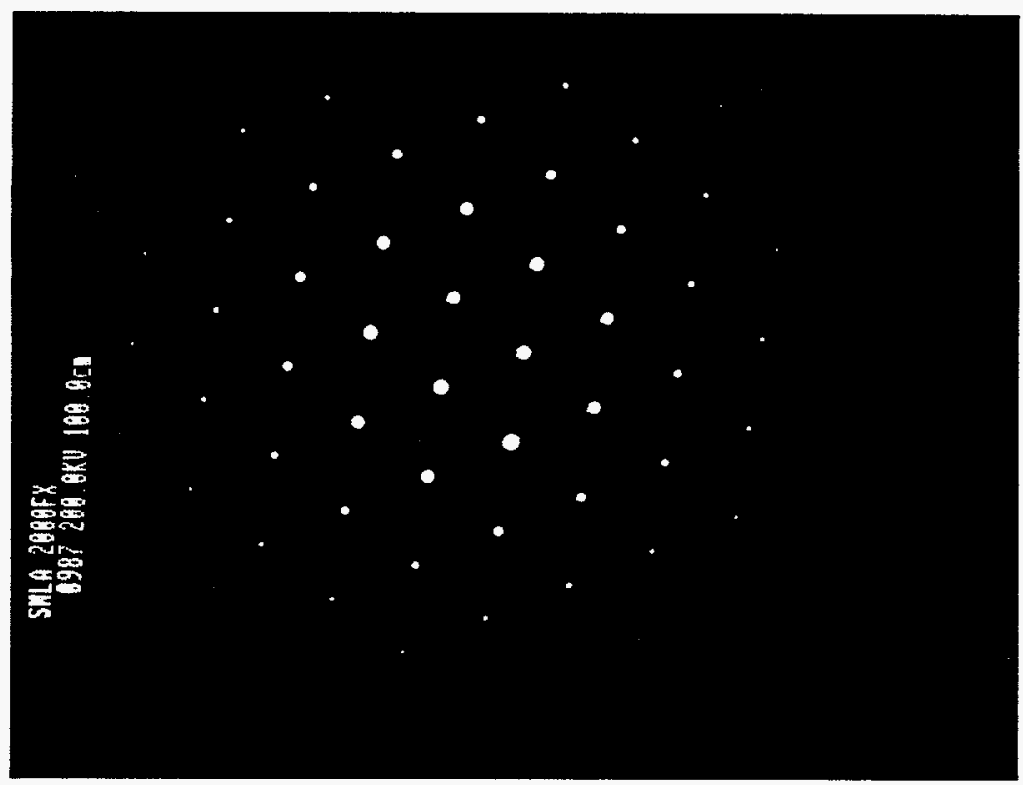

Figure 2

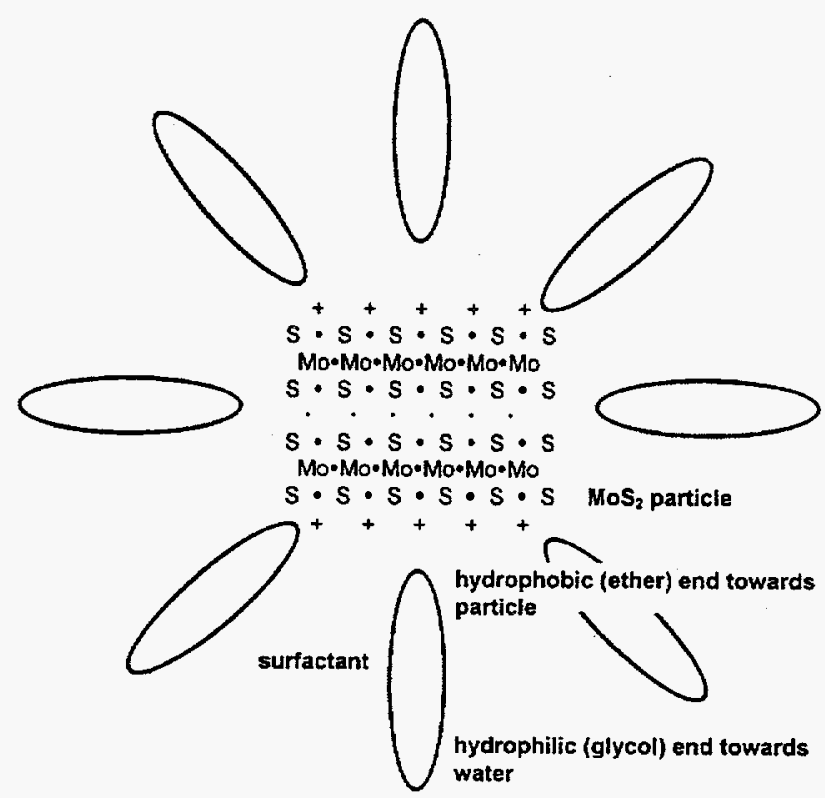

Figure 3

Page 17 


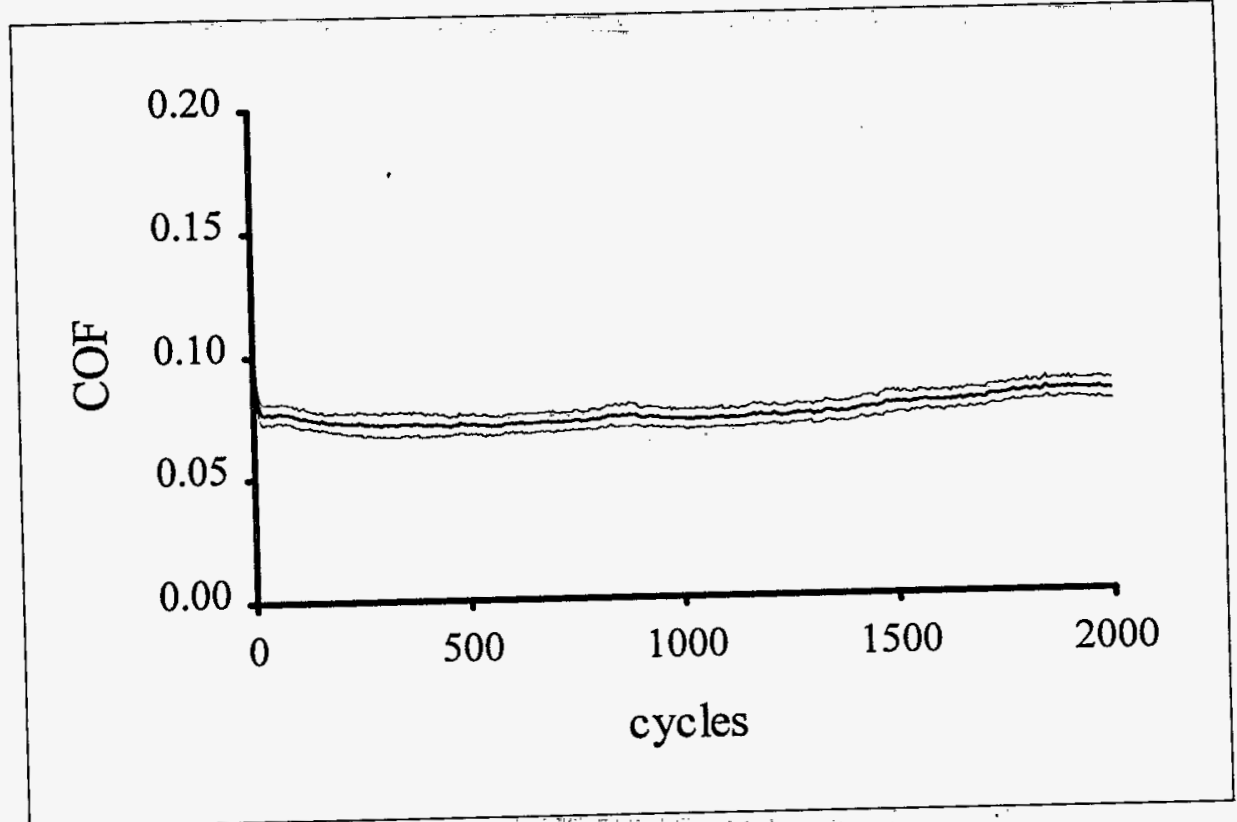

Figure 4

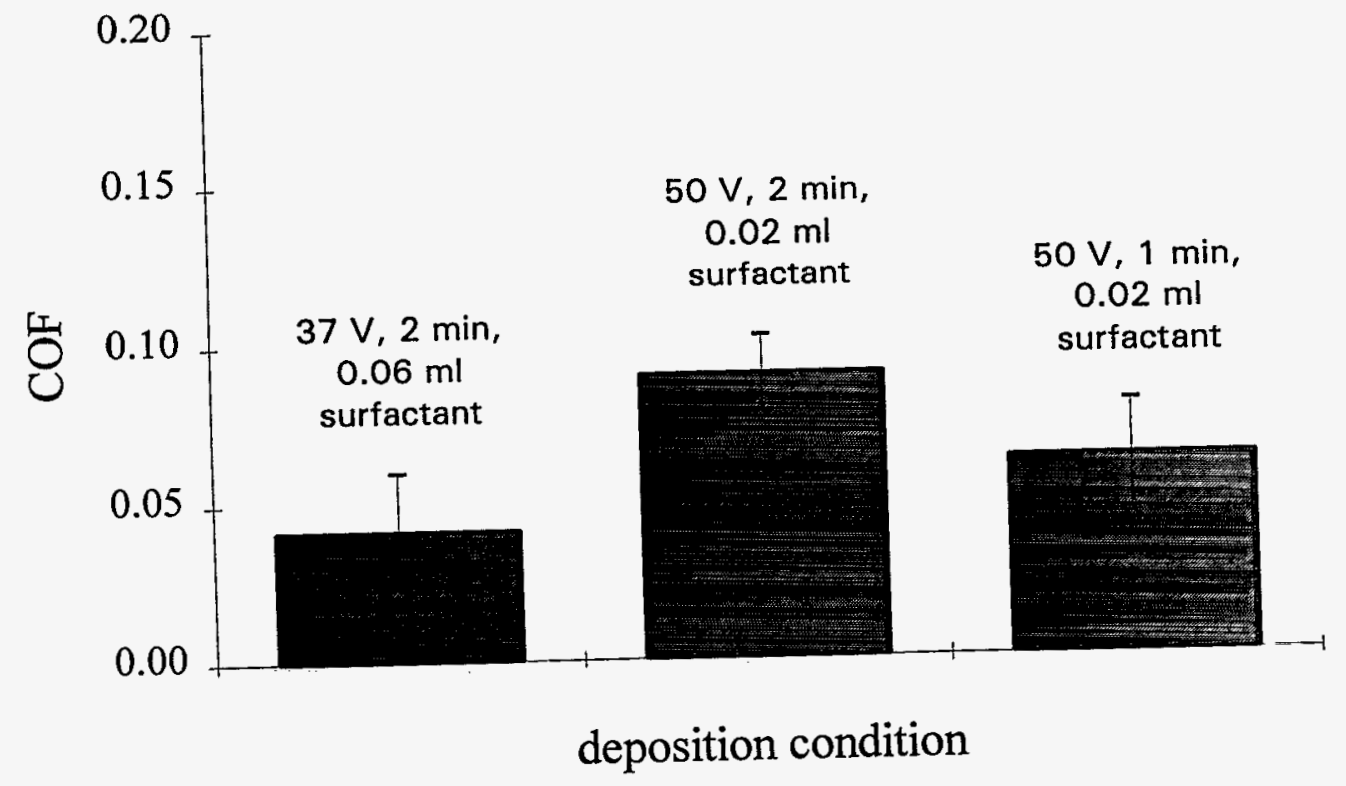

Figure 5 

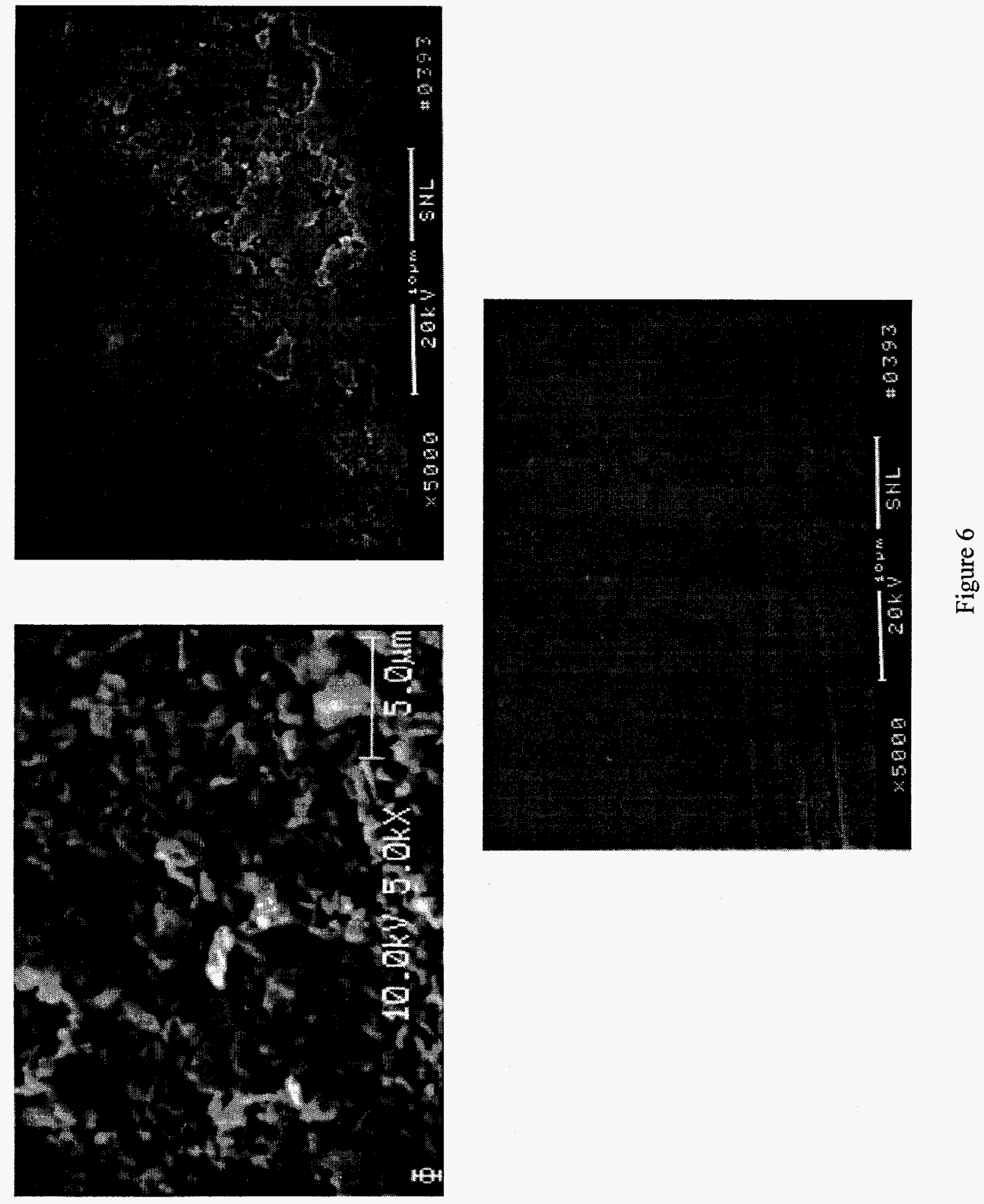

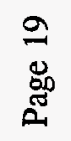




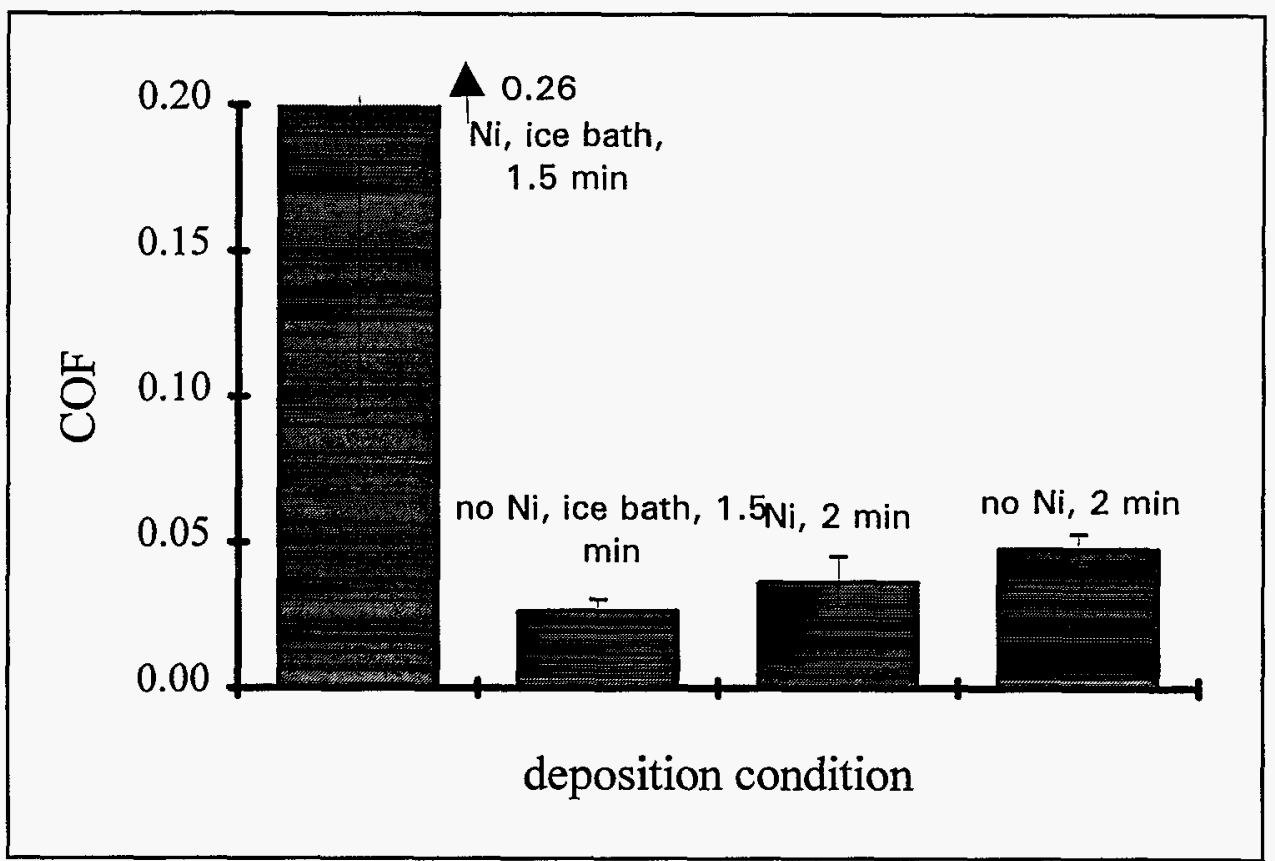

Figure 7

hilo.xIs 


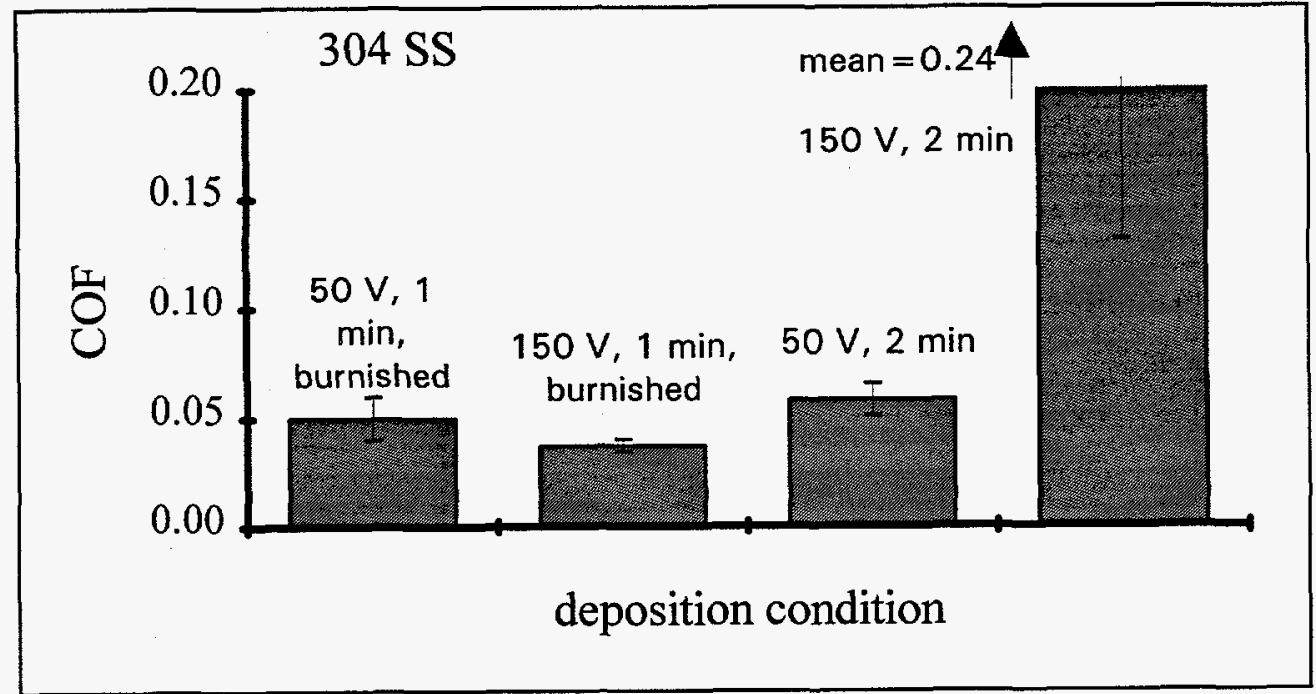

(a)

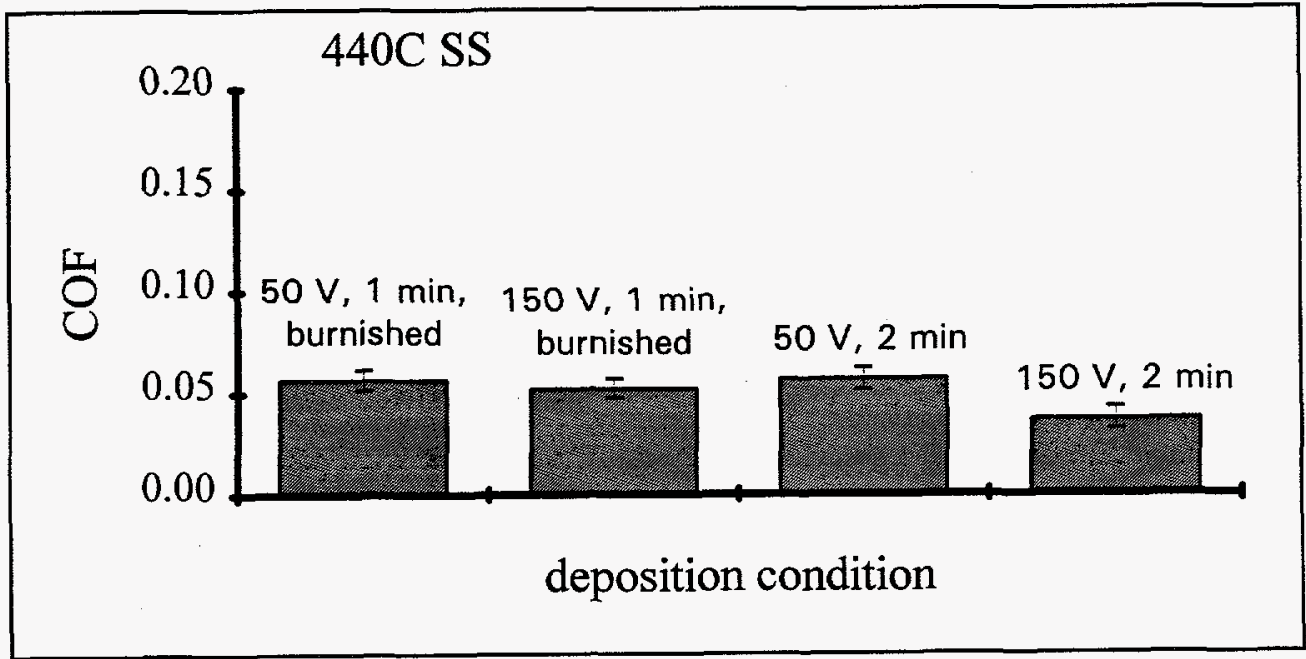

(b)

Figure 8 


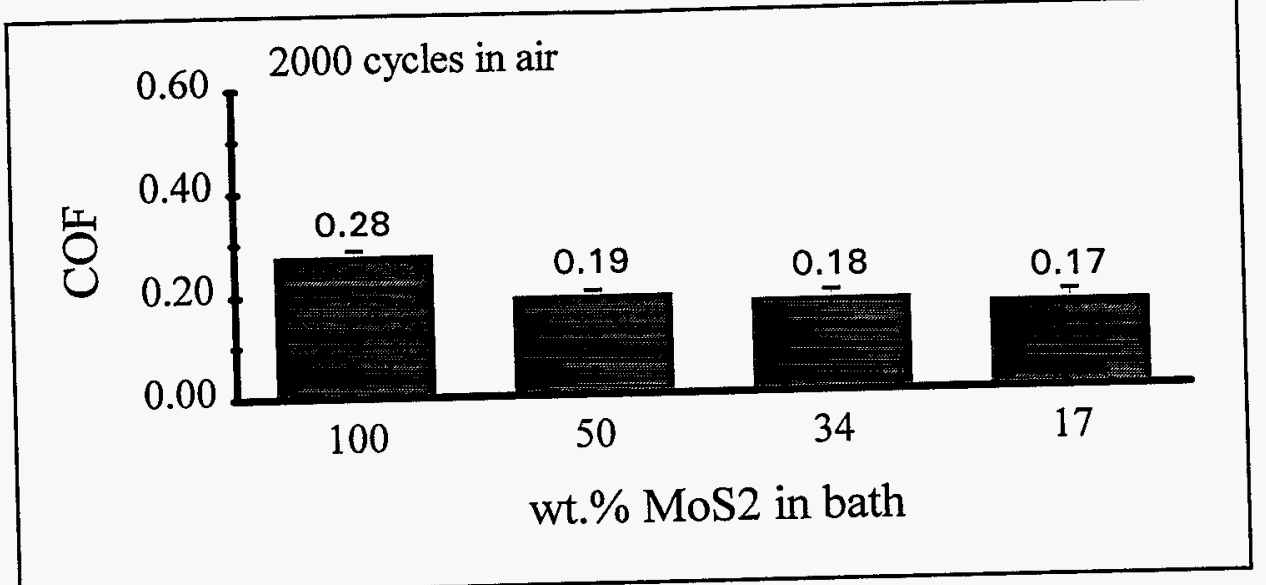

(a)

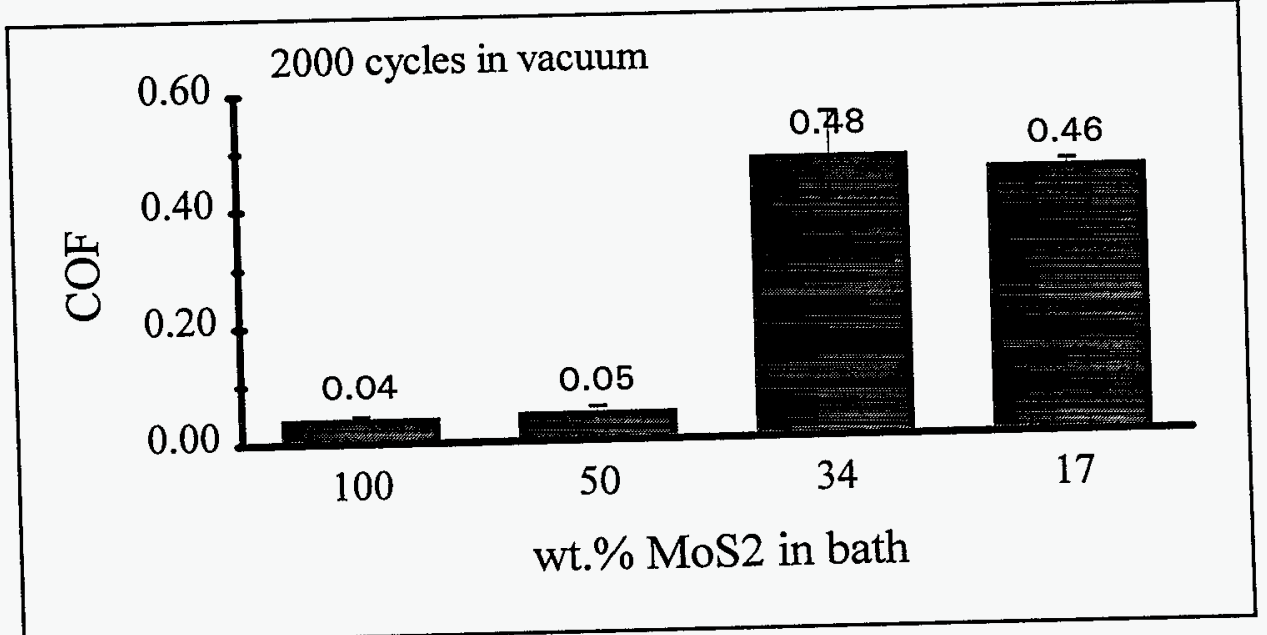

(b)

Figure 9 

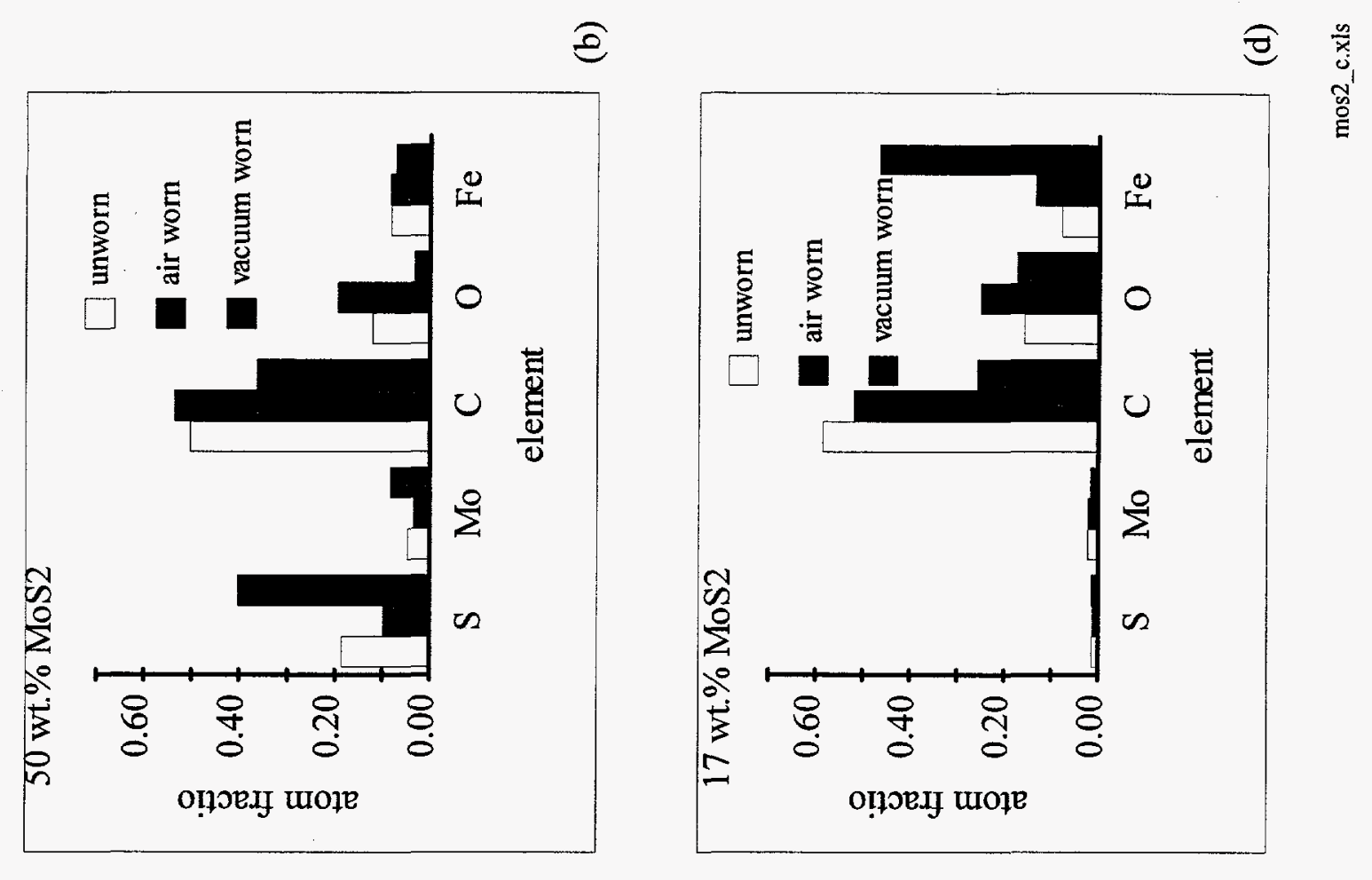

®
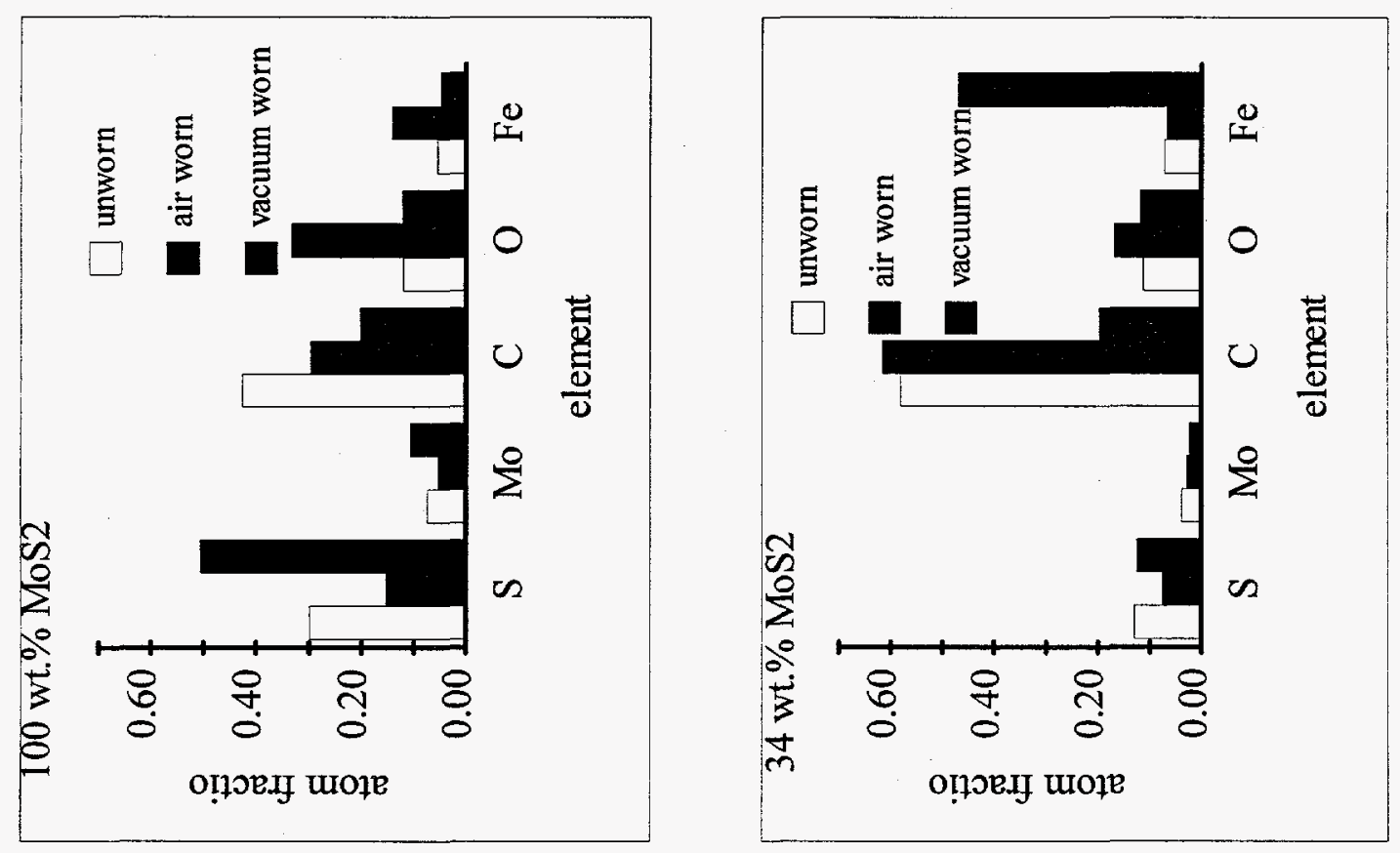


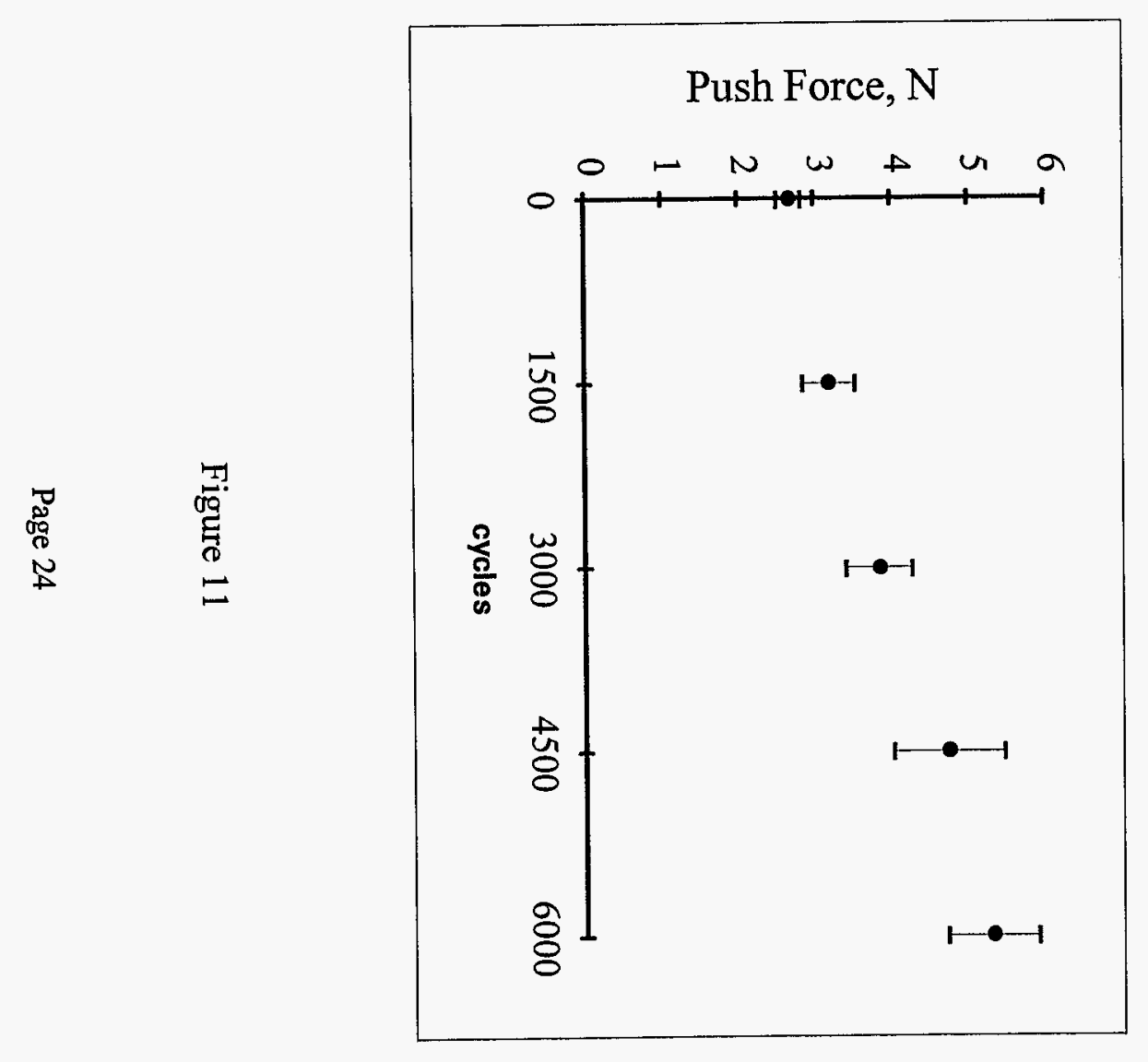

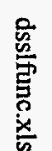

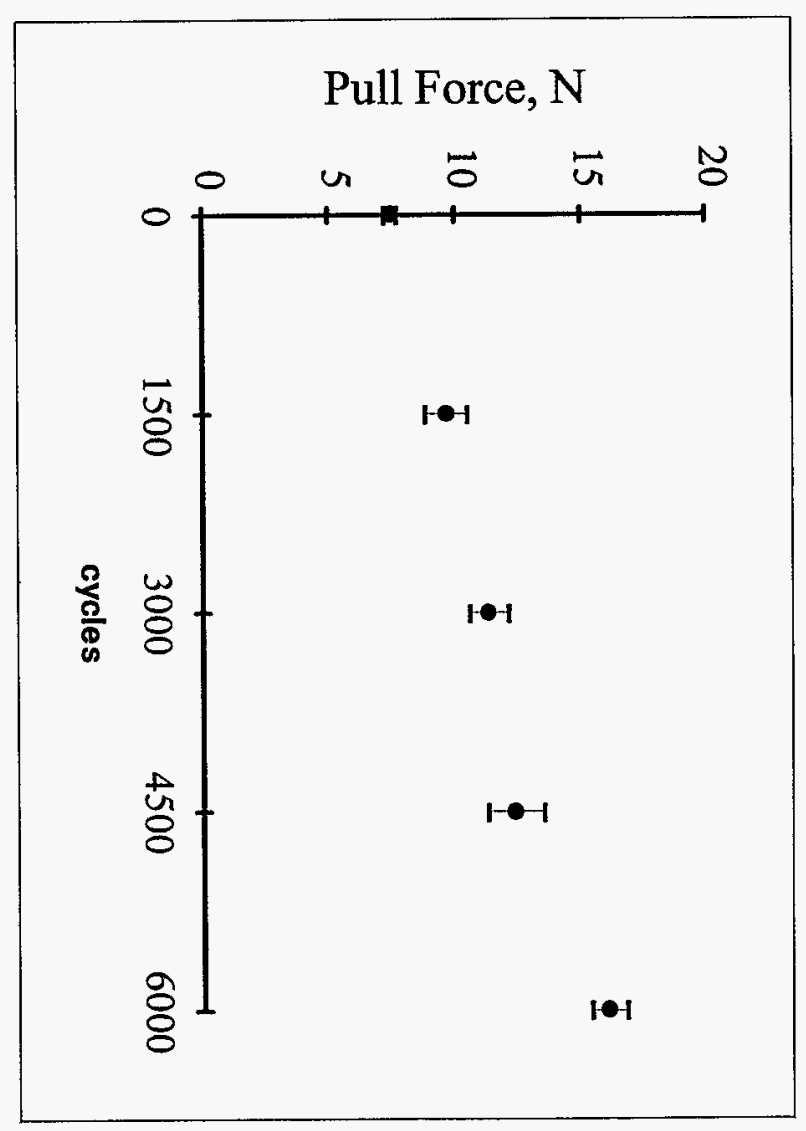

(2) 


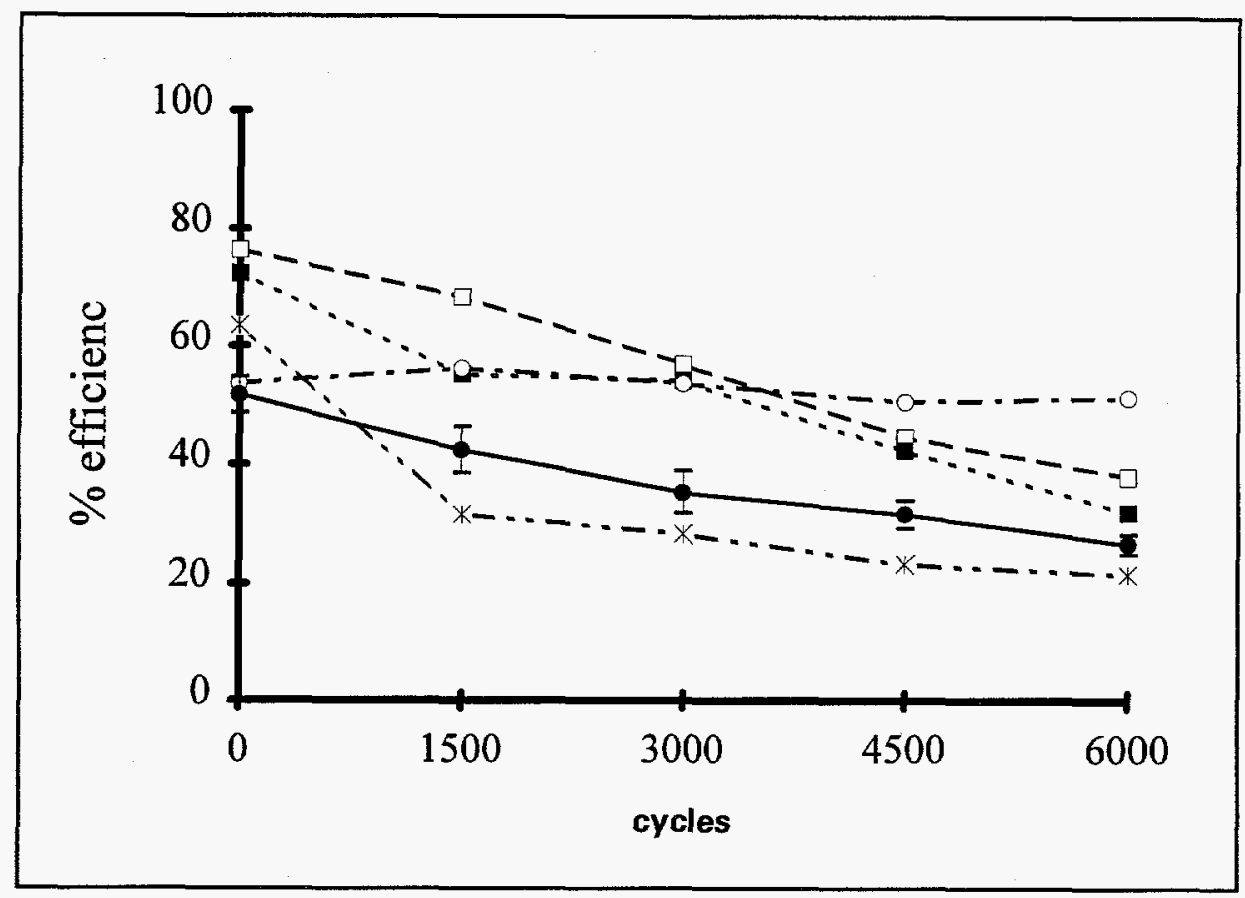

Figure 12 


\section{Appendix A}

\section{LDRD Project Information}

List of publications and presentations resulting from the project.

J.K.G. Panitz, M.T. Dugger, D.E. Peebles and D.R. Tallant, "Electrophoretic Deposition of Pure $\mathrm{MoS}_{2}$ Dry Film Lubricant Coatings," presented at the $39^{\text {th }}$ National Symposium of the American Vacuum Society, Nov. 9-13, 1992, Chicago, IL.

J.K.G. Panitz, M.T. Dugger, D.E. Peebles, D.R. Tallant and C.R. Hills, "Electrophoretic Deposition of Pure $\mathrm{MoS}_{2}$ Dry Film Lubricant Coatings," Journal of Vacuum Science and Technology, Al1 (1993) 1441-1446.

List of invention disclosures resulting from the project.

J.K.G. Panitz and M.T. Dugger, "Electrophoretic Deposition of Dry Film Lubricant Coatings," Technical Advance SD-76,809/SD-5148, filed May 14, 1992.

List of patents resulting from the project.

None.

List of copyrights resulting from the project.

None.

Information regarding employee recruitment as a result of the project.

None.

Information regarding involvement of students in the project.

None. 